\title{
Stage III Oropharyngeal Squamous Cell Carcinoma AJCC v7
}

National Cancer Institute

\section{Source}

National Cancer Institute. Stage III Oropharyngeal Squamous Cell Carcinoma A/CC v7. NCl Thesaurus. Code C8219.

Stage III includes: (T3, N0, M0); (T1, N1, M0); (T2, N1, M0); (T3, N1, M0). T1: Tumor 2 $\mathrm{cm}$ or less in greatest dimension. T2: T umor more than $2 \mathrm{~cm}$ but not more than $4 \mathrm{~cm}$ in greatest dimension. T3: T umor measuring more than 4 centimeters in greatest dimension or extension to lingual surface of epiglottis. N0: No regional lymph node metastasis. N1: Metastasis in a single ipsilateral lymph node, $3 \mathrm{~cm}$ or less in greatest dimension. M0: No distant metastasis. (AJCC 7th ed.) 